\title{
Erratum to: Familial Chronic Granulomatous Disease Affecting Three Siblings and Causing Recurrent Tuberculosis
}

\author{
Noella Maria Delia Pereira ${ }^{1,2} \cdot$ Ira Shah $^{1}$
}

Published online: 10 December 2016

(C) Springer Science+Business Media New York 2016

Erratum to: J Clin Immunol (2016) 36:743-746

DOI: 10.1007/s10875-016-0338-6

Acknowledgements to the article are given below:

Acknowledgements: We would like to acknowledge Ms Manasi Kulkarni and Dr Manisha Madkaikar, National Institute of Immunohaematology, ICMR, KEM Hospital, Mumbai for doing the DHR and NBT tests.

The online version of the original article can be found at http://dx.doi.org/ 10.1007/s10875-016-0338-6.

$\triangle$ Noella Maria Delia Pereira noella_pereira@yahoo.com

1 Department of Pediatrics, Bai Jerbai Wadia Hospital for Children, Parel, Mumbai 400012, India

2 'Torrefiel', 127, Carter Road, Opp. Joggers Park, Bandra West, Mumbai 400050, India 